\title{
Transforming while transferring: An exploratory study of how transferability of skills is key in the transformation of higher education
}

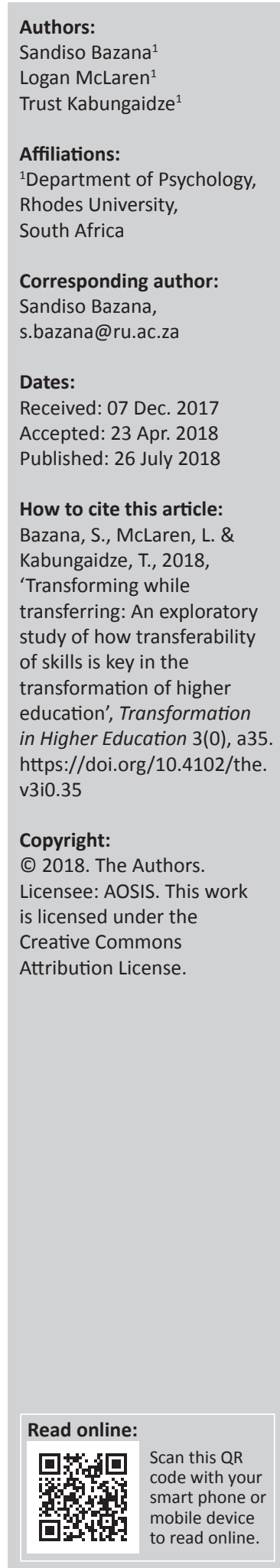

The importance of skills within the transformation of higher education is a crucial factor that has been insufficiently considered. Transformation in terms of higher education forms a fundamental part of the post-apartheid South African society. This transformation movement seems to exclude the possible role and contributions of the older generation of academics. Using a social constructionist viewpoint, this qualitative study sought to bring to the debate of transformation of higher education the important question of skills transferability between older generation academics and the new generation. From interviewing five retired white academics, the study found that institutional culture and implementation of labour legislation through the Human Resources department by the university in question affect the transferability of skills and that proper programmes of voluntary mentorship should be put in place as to allow the growth of both the older generation and new generation academics. The use of new generation academics' perspectives could yield more results and findings that can further this area of study, as well as allow a more diverse and richer understanding of the perception of skills transferability within the transformation of higher education institutions. This further understanding for research is needed to emphasise the importance of knowledge production through the integration of both young academics' as well as older academics' perspectives. This is to be achieved by engaging with other universities and academics, so that a broader analysis of skills transferability within higher education can be understood.

\section{Introduction}

Cloete et al. (2004) describe universities as being the storehouses for informed, critical and inquiring scholars and intellects that have natural talent and that, even though universities are still in the process of restructuring, they are irreplaceable. This statement is important to understand and review as it speaks to the fact that universities play a critical role in producing graduates with high intellect and knowledge. What this, however, fails to acknowledge is the key issue of where these graduates are drawing their knowledge from and whether this knowledge is adequate.

The 2015 Higher Education Summit (HESummit) highlights that approximately $27 \%$ of academics with doctorates are about to retire and that more than $50 \%$ of these professors are the most highly qualified (HESummit 2015). These retirements are associated with the country's retirement age of 65. These are some of the country's most productive researchers. However, this production of knowledge is not being transferred to the new generation of academics by those who have the expertise and skills of teaching and learning as well as research and community engagement. The Human Resource Development Council (2015) states that the gap between supply of graduates and the demand for skills can significantly be reduced if there is a relationship between the business and higher education. The question that bothers the authors of this article is how South Africa plans to utilise skilled and knowledgeable academics before their retirement.

According to McCracken et al. (2017), the human capital theory is made up of human, social and structural capital. This understanding of the human capital theory directly emphasises the importance of skills transferability. McCracken et al. (2017) further states that human capital forms the basis for intellectual capital as it is part of knowledge development, the facilitation of knowledge as well as the sharing of knowledge, all through internal relationships. These factors within the human capital theory allow us to understand the reasoning as to why skills transferability is vital within the transformation of higher education. It is also important to realise that knowledge that is not shared further hinders the process of establishing collaborative approaches for human capital development (McCracken et al. 2017). This is a key disadvantage of 
the human capital theory. However, it provides us with an indication as to why knowledge production can be difficult, and that is because of the fact that either individuals with key skills and knowledge can choose not to transfer their skills or that they have had limited opportunities to do so.

Using the human capital theory to emphasise the importance of knowledge and skills of a workforce (McCracken et al. 2017), this study aims to highlight issues in terms of institutional culture and race as well as establish and highlight the problematic issue of skills transferability within higher education between academics. Key to this realisation will be in looking at the acts, particularly the Employment Equity Act (EEA) of 1998 and Skills Development Act (SDA) of 1998 as well as the New Generation of Academics Programme (nGAP), and providing guidance on how to better implement such interventions to establish an environment of shared knowledge and experience, that will aid in the transformation of higher education.

\section{Brief literature review}

'Skills' are defined as the knowledge and capabilities one has to perform certain tasks and abilities according to expertise and competencies (Amos et al. 2008). The HESummit highlights the notion that a new generation of academics needs to be produced and trained to create a better and more effective knowledge generation of quality (HESummit 2015). They further emphasise the importance of this by stating that the failure to invest in a new generation of academics will have consequences to the extent that social equity and the scope of deracialising and degenderising of the workforce will be directly affected (HESummit 2015).

Another crucial factor stated by Amos et al. (2008) is the notion that a minority of a country's skills are produced through qualifications and that the largest share of skills development is from the physical workplace. The human capital theory emphasises that investment into education and skills with continuous development proves to be beneficial (Nufakho, Hairston \& Brooks 2004). Although this theory looks at the need for human resource development to play a key role in organisations, this is not always possible because of the misguidance of policies and procedures that aim to integrate this theory into policy implementation. During the post-apartheid reform and reshaping of higher education, there was immense pressure on the need to redress the equity of employment and skills between white academics and black academics (Cloete et al. 2004). This was also emphasised in the EEA, which was created to redress the injustices and discriminations of the past through achieving a diverse workforce, creating equal opportunities and promoting the constitutional right of equity (Government Gazette 1998).

The term 'transformation' within higher education is widely debated, but it mainly refers to an ongoing and rooted process that aims to reconstitutionalise and develop universities so that they represent and reflect the apparition of a democratic society (HESummit 2015). This further emphasises the need for universities to remove any forms of discrimination while simultaneously looking at creating an educational environment that promotes the talents and abilities of all South Africans particularly in relation to those from designated groups (HESummit 2015). Within the efforts to create and transform South African universities, Badat (2010) highlights some crucial aspects that were to be addressed in terms of their achievements thus far, as well as possible issues and concerns that they may face. These key issues included mediating competing goals, post-school education, differentiation and diversity, the diverse purposes of higher education, adequate state funding, intellectual spaces, current postgraduate output levels, creation of new generation academics, remuneration of academics as well as access, opportunity and success in higher education (Badat 2010). Within the white paper that was approved by cabinet in 2013, the main policy objectives were to address the areas surrounding education and social justice, encouraging a single and coordinated system of institutions, expanding access, improving quality, increasing diversity and addressing the objectives of education and work as well as responsiveness (DHET 2013).

Particularly, Badat examines the importance of deracialisation and decolonisation of institutions when looking at these core issues and how, in doing so, the injustices of the past can be addressed (Badat 2010). These core aspects of transformation are fundamentally important and should be strongly evaluated and incorporated into higher education systems, as this lays the foundation for majority debates within the discourse surrounding transformation. However, there is an observed sentiment of racialisation of the needed transformation in higher education sector, and in the process the contributions of the older generation of academics, specifically acknowledging those who have expert knowledge and skills regarding their field of study, tend to be overlooked (Badat 2010; Boughey 2002). This observation needs to be addressed using effective and well-reasoned intervention strategies, so that the transformation of higher education can be more effective in yielding positive results.

Badat (2010) raises the concern that certain trade-offs are being made between quality and accountability in terms of redressing injustices of the past and adhering to policies and government requirements. He states that new generation academics should mainly include women and black academics, but that these academics need to possess the intellectual and academic capabilities related to teaching, learning, research and community engagement - that is, the skills necessary to be an academic (Badat 2010). In this regard, individuals who possess the job need to be able to perform the tasks and duties that are required of them. This is an important concept to grasp, as without skilled labour there can be no quality of results (Akojee \& Nkomo 2007).

This perpetuates the need for human capital to be a criterion in terms of staffing academics within an institution. Badat (2010) argues that these academics need intellectual and academic capabilities, but he does not consider where these capabilities will come from. The idealism that designated 
groups will be placed into a position of power according to their individualistic or biological characteristics, which make them suitable candidates, needs to be addressed. The human capital theory emphasises the fact that the understanding and learning of individuals within organisations needs to be invested in (McCracken et al. 2017). This article suggests that the older generation of academics must be utilised effectively for Badat's suggestion to be realised.

Yes, there has been criticism of the knowledge that these academics possess, with some arguing that it is disconnected from their context and therefore undesirable (Cloete et al. 2004); however, the study still maintains that sharing of skills, knowledge and experience remains central to an effective transformation of higher education. In fact, this is what has led to racialisation of the need for transformation. Older white academics have been viewed as protectors of loosely defined 'white privilege' and 'whiteness' (Vincent 2015) and therefore protectors of the status quo, which needs to be changed. The development and collaboration between those with the skills and capabilities and those in the process of acquiring them is crucial in the process of higher education transformation.

Policies and regulations seem to be reiterating the idealism of meritocracy, as also acknowledged by Cloete et al. (2004), who argue that policy outcomes were hardly ever the same as policy intentions within the process of policy implementation. Cloete et al. (2004) further signify that there was a decrease in white male academic staff and an increase in black academic staff as well as women (both white women and black women). The increase in black academic staff and women within higher education positions is both beneficial and a success in redressing past injustices. However, academic integrity was severely tested because of the need for institutions of higher learning to redress programmes and procedures, as this meant an increase in job losses that may occur (Cloete et al. 2004) and the jobs were those of older white academics.

This could result in the skills of older generation academics being ignored as it becomes more important to redress imbalances and adhere to policies such as the EEA rather than to involve these academics in improving new generation academics' understanding and expertise. This will help them to build on their knowledge and gain more experience and qualifications as required by the SDA (Boughey 2002).

The pressures of South Africa joining a rapidly globalising economy has put emphasis on South Africa producing a skilled workforce, but this often contradicts the notion of achieving equity within the workforce itself - especially with regard to access to higher education (Boughey 2002).

Cloete et al. (2004) further state that there is a widening gap between politics and political programmes on one side and the dynamics of the public sector, higher education included, on the other and that, because of this gap, policy outcomes will hardly portray policy intentions. This misguidance of policies and procedures within the transformation process is an important realisation as the need for a skilled workforce within South Africa, particularly higher education institutions, is a necessity to produce quality graduates and for knowledge production (Akojee \& Nkomo 2007). Akojee and Nkomo (2007) further argue the importance of quality and that this needs to be known if one is to redress the imbalances of the past and to realise that quality should be understood through the ideas of redress, equity and access. Akojee and Nkomo (2007) state the same factors of the human capital theory in that quality access cannot be achieved with limited resources and that, through a diversified combination of people and resources within an educational institution, there will be greater potential for high quality information, research, scholarships and community service.

\section{Society and higher education}

Universities are viewed as microcosms of society. As such, any socio-political transformation in a particular society directly influences the nature of higher education institutions. Transformation in terms of higher education forms a fundamental part of South African society post-apartheid, as Badat (2010:2) states that 'there has been a wide array of transformation-oriented initiatives seeking to effect institutional change'. During the increasingly changing global context and within 6 months of the first democratic election, President Nelson Mandela established the National Commission of Higher Education, whose central mission yielded two important tasks (Cloete et al. 2004).

The first task was to remove any abnormalities within higher education that were caused by apartheid, and the second was to modernise higher education by combining it with international experience and best practices (Cloete et al. 2004). The accomplishment of these tasks could prove beneficial to the workforce of South Africa as well as the economy of South Africa, as the human capital theory states that the training and education of people have a direct impact on organisations and societal operations (McCracken et al. 2017). This theory, as with the systems viewpoint theory, suggests that no two environments can work independently of one another and that they influence each other constantly (McCracken et al. 2017). This is important for higher education institutions as well as governments and societies to realise, as the success of transformation in one environment will affect the operations of the other. This then also contributes to the reform of institutional culture that must take place to make way for new and inclusive changes in higher education institutions. This is a difficult task, or better yet, ideal to accomplish within the context of South African higher education. This is because of the indiscretions of the past as well as individual differences, explicitly looking at race and ethnicity, within the context of a rapidly changing workforce and social environment (Cloete et al. 2004).

At Rhodes University, a survey was conducted to best understand the values and understandings staff members had regarding transformation of the institutional culture (Rhodes University 2014). Similar surveys were conducted at other 
universities such as University of Cape Town (UCT) in 2007; University of Johannesburg in 2012 and Nelson Mandela University (NMU) to name a few. The Rhodes survey found that between $50 \%$ and $53 \%$ of staff members considered Rhodes to be dedicated to transformation and redressing the injustices of the past (Rhodes University 2014). The survey states that, although there is a need for transformation, as only $37 \%$ of white staff members agreed with this statement (Rhodes University 2014). This is a troublesome figure with further research showing that, although $90 \%$ of African staff agreed with the need for transformation, they were the least convinced that Rhodes was instigating transformation within the university operations (Rhodes University 2014). The racial tensions become obvious also in the way students' demands for transformation are expressed and the emphasis on employment of equity candidates. This survey further emphasises the need for transformation to be successfully and noticeably implemented within higher education institutions, as this speaks to the racialising sentiments of students that aggravate tensions and resistance to transformation, which then imbues the debate with the 'blacks in, whites out' discourse.

Within the early stages of transformation, equity became a core focus of higher institutions, as it was perceived as their duty to redress past imbalances that occurred within 'white institutions' (Boughey 2002). However, there has been a shift from equity to efficiency in terms of skills because of the implementation of the Skills Development Act of 1998, which was designed to produce a workforce needed for economic growth (Boughey 2002).

\section{Race in higher education in South Africa}

Transformation in South Africa started as a highly racially charged debate. Institutional culture is central to the understanding of race dynamics in higher education (Vincent 2015). To correctly understand the importance of institutional culture and recognise its importance in terms of the role it plays within the transformation of higher education, there is a need to identify the key areas that institutional culture directly affects.

Vincent (2015) states that institutional culture is the lived experiences of every individual who populates the institution, be they student, academic staff, management, support staff or community member with some connection to the institution. It is further stated that this culture must then encompass the practices and policies of those who are part of the university past and present (Vincent 2015). However, within institutional culture, there is a perception of what is normal - the perception of 'cultural whiteness' and the privileges associated with this term (Vincent 2015).

In South Africa, because of apartheid, the majority of academic knowledge has been produced largely by white men; to address this, special initiatives and measures need to be considered that allow for previously excluded social groups to be introduced into the production of knowledge (Badat 2010).
The human capital theory (McCracken et al. 2017) further acknowledges this need for more individuals within the workforce, as new employees who have different mindsets and skills could greatly benefit the production and growth of the organisation. However, regarding higher education institutions, those who have the expertise and skills of teaching and learning as well as research are not transferring this production of knowledge to the new generation of academics, as it is perceived that those with the skills are majority white academics - and therefore uncooperative individuals.

\section{Institutional culture}

According to Vincent, institutional culture expresses itself in the discourses and material conditions of the university (Vincent 2015). Institutional culture has been identified as being resistant to change. Looking at both the USA and South Africa, which both have histories of racism, not only is there a need to overcome discrimination with regard to access to higher education, but also the racial dynamics at the core of the institution need to be addressed (Gordon 2015). This is not only in the case of access for students to higher education but academics as well. Vincent (2015) further argues that although laws and policies may change, the social and cultural structures, practices and habits remain the same. This is true within South African universities, as many were built on a foundation of white supremacy, and according to Waghid (2002), still perpetuate patterns of injustice.

This realisation within a post-apartheid South Africa brings about the need for structural and social change amongst how higher education institutions operate. Thus, there is a need for cultural change in order to incorporate the diverse beliefs, understandings and values of the entire South African society and not just a minority group - Vincent (2015) asks whether it is possible to achieve excellence under exclusionary and discriminatory circumstances, because this limits the possibilities of knowledge and exchange of experience. Vincent (2015) further states that institutional culture is one of the main obstacles to transformation in higher education because of the high resistance to change. This poses a threat to institutional transformation, as change is not only observed from the viewpoint of new generation academics, but older generation academics as well.

The full report of the Rhodes Institutional Culture Survey was done in 2014 to gain a broader understanding of how culture affects the environment in which Rhodes staff operate and how the culture of the university could be improved. The report showed that only an average of $56 \%$ of all staff members were satisfied with the equity and fairness of Rhodes University, with the lack of fairness and equity being felt according to race and seniority amongst staff members (Rhodes University 2014). Another concern in this report was that all other races, other than white staff members and Indian staff members, felt less valued within Rhodes University (2014). This indiscretion is detrimental to the operations of the university, as the human capital theory states that a person's learning capabilities are comparable to other resources used 
when producing goods and services (McCracken et al. 2017). This suggests that, if a person feels devalued and that they are not being treated with fairness, their work ethic as well as quality of work produced will decrease, as they are not motivated to produce the best results. The differentiation of age within the university is also addressed in terms of how valued each age group feels within the university (McCracken et al. 2017). The survey suggests that the under- 26 category felt negatively valued compared to the older generation, who felt more valued, but there was an overall low agreement rate with the notion of being valued at Rhodes University (McCracken et al. 2017).

The implication of how age affects a person's capabilities is further looked at within this study and will be a contributing factor of looking at the institutional culture of Rhodes University and the operations of academic sustainability. The sustainability is further emphasised by the human capital theory, as this article argues that the gain of knowledge and resources in terms of training is an investment in human resources (McCracken et al. 2017).

\section{Intervention strategies}

South Africa is faced with a situation of a trade-off between two crucial aspects of development as well as redress and to rectify this, there is a need for collaboration between these two policies of the EEA and the Skills Development Act within higher education if transformation is to be achieved effectively. This is also important, as adherence to the policies in the most beneficial way to address issues of developing a more skilled workforce as well as creating a more diverse workforce, is a crucial aspect to take into consideration. The redress of both acts is important for the procedures of change within the South African workforce; however, the need is great for both acts to be re-evaluated, and perhaps even combined or changed, for the effective redress of past injustices as well as the effective implementation of skills development programmes.

The nGAP involves the recruitment of highly capable scholars as new academics looking carefully at balanced equity measures considering areas in the greatest need (DHET 2015). This programme is one of the biggest implemented by the Staffing South Africa's Universities Framework, with the first intake having more than 125 posts advertised in the Mail and Guardian as well as the Sunday Times newspapers during May 2015 (DHET 2015). The programme aims to run over 6 years, the first 3 being a development programme funded by government and then a 3-year induction period thereafter (DHET 2015). This programme aims to develop long-term staffing plans - looking at growth and equity, anticipated retirements of staff as well as attrition rates beyond retirement (DHET 2015). The nGAP launched at Rhodes University in 2001 and helped to refine this programme for the past 15 years; it aims at providing a rigorous application process for top black women academics whose research and teaching development is built on in the programme (Dugmore 2016). This programme allowed academics to take part in a 3-year programme under the guidance of a mentor identified by the university and in collaboration with the Centre for Higher Education, Research, Teaching and Learning (Dugmore 2016). This programme allowed academics to acquire knowledge in the working environment as well as incorporate their own ideas and knowledge into the institution, as they were given some autonomy in their decision-making and ways of teaching (Dugmore 2016).

However, Hlengwa (2015) argues that, although this programme has helped improve equity within the institution, there is a consensus that the university acquired 'safe bets' when filling these positions. These safe bets are so-called privileged individuals who meet the equitable requirements of the institution and who, because of their educational background and middle-class status, would not challenge (nor be alienated by) the culture and operations of the university (Hlengwa 2015). Hlengwa and five other participants took part in a study that found that majority of the participants 'fitted in' in terms of their cultural capital, but one participant went on to say that 'I do not see myself fitting in to Rhodes University at heart, never into the whiteness of the culture' (Hlengwa 2015:153).

Deducing from Hlengwa (2015), in part, the nGAP can be seen as an important strategy to capacitate the beneficiaries (black people and women) - however, in terms of transforming the institutional culture, the nGAP takes a moderate approach. This is a problematic statement, as this can mean that these academics are not necessarily contributing to the change in transformation at higher education institutes (Hlengwa 2015). This is challenging because it does not foster a change in institutional cultures that reflects the diversity of South African cultures. As Minister Naledi Pandor opines, 'institutional culture is embedded at many different levels and requires both changes in structure as well as in attitudes and consciousness on the part of academic staff and administrators' (Makgoba 2004). Therefore, Hlengwa's assertions about the so-called safe bets is an indication of the universities' unwillingness to change.

\section{Aim and research questions}

The main focus was on the role that transferability of skills could play in the development of a successful and transformational environment of higher education. The study asks the following questions.

- How would this realisation of the importance of skills transferability affect the ways in which transformation takes place?

- Is there a difference in the quality of education between older generation academics and new generation academics because of different skills within their respective teaching abilities and knowledge production?

- Are the skills and competencies of older generation academics being valued and integrated into their field once they retire, or are they deemed useless and unimportant concerning the new generation of academics? 
- How could collaborative effort between these two different academic generations help in transferring skills and aid in the transformation of higher education institutions?

\section{Research design}

This research study took the form of an explanatory study, as the aim was to explore and gain new insights and ideas about certain phenomena (Van Bruggen 2001). Qualitative measures were used to gather information and sampling was performed using the method of snowball sampling, where a certain participant who was relevant to the study was purposively contacted and then, through this participant, contacts with others who would participate in the study as well were established (Bryman et al. 2014).

The study used the insights of five participants who had retired from a historically white institution (HWI) and were over the age of 65 . The small sample size was used because of the thematic nature of the methodology for this research, as the aim was to gain extensive insight from these participants and use their knowledge and answers to determine themes and critical issues that would address the research questions (Braun \& Clarke 2006). This older age group was used because the knowledge and experiences they have are vital to consider for their research fields within academia. The human capital theory supports the need for skills and experience to be part of the training and development process of new staff, and this study helps emphasise this need (McCracken et al. 2017).

A social constructionism viewpoint was taken when conducting and analysing information because social constructionism looks at experience and understanding through social structures (Neuman 2014). In-depth interviews were used to gain the information needed; this is an interviewing technique of data collection that is used when specific topics are being discussed (Berndt \& Petzer 2014). Questions were asked in a semi-structured way so as to allow flexibility of answers.

\section{Procedure of data analysis}

The data from the interviews were processed and analysed using a thematic breakdown to identify the prevalence and importance of specific ideas that were mentioned in the interviews (Braun \& Clarke 2006).

A thematic analysis aims to interpret various aspects of the research topic and identify themes in the data gathered (Braun \& Clarke 2006). An inductive and latent thematic analysis was used to determine the underlying meaning of the data gathered and to identify similarities in responses (Braun \& Clarke 2006). Thematic analysis helped provide insight as to how underlying meanings shape certain themes and assumptions not previously researched (Braun \& Clarke 2006). The steps outlined by Braun and Clarke (2006) were also used when analysing our data from the interviews. These include the following: (1) familiarising ourselves with the data by reading and rereading transcriptions; (2) generating initial codes by looking at data that may show initial meaning;
(3) finding themes by sorting and grouping codes together; (4) reviewing and refining themes to ensure coherence and validity; (5) defining and naming themes by ensuring they answered the research question; and (6) producing themes in the report and ensuring they were justified by referring to our extracts and interview data (Braun \& Clarke 2006).

The steps of Braun and Clarke (2006) were important to consider when analysing and making sense of the raw data gathered in the form of the interviews. These steps are guidelines within thematic analysis and help ensure the rigour and trustworthiness of the data (Braun \& Clarke 2006).

The main research question was on the role that transferability of skills could play in the development of a successful and transformational higher education environment. The participants interviewed were all between the ages of 65 and 75. Table 1 outlines the demographics of the participants as well as the pseudonyms used when discussing their results.

TABLE 1: Demographics of the participants' identities.

\begin{tabular}{llll}
\hline Participant & Race & Gender & Pseudonym \\
\hline Participant 1 & white South African & Male & Mason (M) \\
Participant 2 & white South African & Male & Roger (R) \\
Participant 3 & white South African & Male & Pike (P) \\
Participant 4 & white South African & Male & Will (W) \\
Participant 5 & white South African & Female & Sue (S) \\
\hline
\end{tabular}

Pseudonyms were used as this allowed for complete anonymity of the participants. Once this was done, the transcribed interviews were collated by first identifying codes and words that were deemed important and related to the research questions and then grouping the codes according to their similarities in meanings. Once this was achieved, the three themes then emerged, with each having two sub-themes. They can be outlined as follows:

(1) 'The formal message'

(a) 'By order of the pension fund'

(b) Academics - one's true value

(2) Transforming an institution

(a) 'The Buzzword'

(b) The alienation of institutional culture

(3) A collaborative approach to mentoring
(a) The gap in nGAP
(b) The informal of the formal

\section{Results and discussion}

Each of these themes holds significant insights into the need for skills transferability within transformation of higher education. To understand this, each theme will be looked at in detail; using extracts taken from the interviews, this article aims to highlight the importance of this gap of skills transferability within the discourse of transformation in higher education.

\section{'The formal message'}

This theme was the most common theme that emerged during the interviews, where participants reached the same 
conclusions as to what their age meant to the procedures and labour policies of the university as well as which characteristics they possessed were deemed more important in terms of the university's expectations. This main theme allowed two sub-themes to emerge and each discussed the 'formal message' that the university seems to portray to the older generation of academics.

\section{'By order of the pension fund'}

The pension fund of this university (2015) stipulates that all academics must retire at the age of 65 and that one can retire later but not beyond the age of 68 . This was stated by the participants in a manner that suggested that the university regards them as disposable at this age. Participant $M$ said:

'Uh ... ya. I sat with a bit of hesitation because [in] part of the contract it was kind of assumed that one retires at 65 , even though many of the other universities and the government itself says that there is no mandatory retirement age.'

W elaborated on this general understanding and went on to state that the university may hire a retired academic back on contract but that whether this action is taken or not, any academics at the age of 65 must retire.

'Oh yes, I mean the (university) ... pension fund is a private fund, um, and that is statutory in terms of the rules of the pension fund. Ya ... ya, so you have to retire in the year in which you turn 65. The university is free to give you an extended contract or whatever, but you have to be taking your pension. You can't, your posts are no longer pensionable beyond the year in which you retired.' (Participant W, male)

Another participant, R, also suggested this and elaborated on his reasoning for retirement to be because of the fact that he was over the regulatory retirement age of 65 :

'Well ya, it has regulations in [the university] and ah and I suppose in a way it was and um ... I had already, you know, exceeded the the um, retirement age by quite a lot of years.' (Participant $R$, male)

The participants expressed the fact that the university did have a mandatory retirement age and that this age was one of the main reasons for their retirement, not unwillingness to stay within the university. The HESummit (2015) states that approximately $27 \%$ of academics with doctorates are due to retire and that more than $50 \%$ of these professors are the most highly qualified. This is concerning for universities as the skills of these academics are needed to further develop their fields, but is the importance of these skills recognised by these universities or is the mandatory retirement of the academics more important? The retirement reform fund suggests that retiring workers need to be given retirement annuity options and that only after the employee makes a choice can the organisation categorise the retired employee into this annuity (National Treasury 2004). Rhodes University has given these options to their staff as this is a mandatory requirement from the national treasury (Pension Fund of Rhodes University 2015); however, this is a monetary value that is placed on the academics and has no relation with the skills and work that they have done within the university. The retirement reform policy further states that its objective is to ensure that retired employees are able to save adequately through retirement funds and that the employer is liable for any failure to transfer collected retirement contributions into a retirement fund (National Treasury 2004). This seems to be an adequate and helpful policy for retiring employees, yet human resources only applies this fund as a monetary expense to the institution and therefore still does not recognise the academic for their skills. This policy is therefore needed to help aid academics in terms of their retirement, but the human resources department must ensure that the implementation of this fund be communicated to staff as an acknowledgement of their hard work within the university and not just a final pay-off to ensure they are finally gotten rid of.

\section{Academics - One's true value}

An unnerving theme that was discovered within the participants' transcripts was that they seemed to know how to overcome the mandatory age of retirement and that they needed to become as indispensable as possible. This speaks to how participants perceived the university and, specifically, the human resources department as opposed to the academic faculty in which they worked.

One of the main findings that emerged was that the human resources department was very abrupt towards these older generation academics, with many of them voicing the opinion that human resources was disinterested and abrupt towards them. For instance:

'Ya, I really was forced and that particularly this year where instruction came from $\mathrm{HR}-\mathrm{xxx}$ will not appoint in any capacity $x x x$. It was as blunt as that ... um and I don't think my particular contribution has ever been properly valued by this place.' (Participant M, male)

In his statement above, M expressed that the human resources department was quite adamant that he should retire and this shows in how he stated that the university had not recognised his contributions. This is also important to realise, as the human capital theory states that all skills and knowledge should be invested in (McCracken et al. 2017). Therefore, the university not recognising these contributions shows a lack of regard for the importance that $\mathrm{M}$ could play in the transferability of skills and the growth of other academics within his field of expertise:

`No, none whatsoever and, in fact, last year when they were wanted to get my contract renewed, I had very, very poor treatment from HR. My case, and look, I don't stand on ceremony or anything like that, but I do think I'm a senior professor.' (Participant S, female)

Although participant $S$ did not regard herself as superior, she did speak to the fact that she should be respected and that the human resources department had no respect for her, as her contractual renewal was deemed unimportant and simply passed down for someone else to handle:

'And the whole thing was delegated to a fairly junior person in HR and I got a letter form HR that, that I quite resented. So I haven't found their input at all impressive.' 
From the above extract, it is clear that participant $S$ also showed dejection for the human resources department, which also suggests that the university did not value her. This dejection and contempt was also described by participant $\mathrm{W}$ in the extract below, as he also pointed out that the human resources department did not seem the least bit interested. Amos et al. (2008) state that the human capital of the business is one of the most important factors to consider if the organisation wishes to remain effective. This does not seem to be of interest to the human resources department, as participant $\mathrm{W}$ also stated that the humanisation of the university was not considered - especially in relation to the staff:

'HR - they didn't seem the least bit interested. I said, you know, the university considering the people ... So, and I said you know, considering that some people put their whole working lives into this. The least you could do is offer some counsel or maybe even just a support group. I mean I don't like to cast myself as the victim and I may sound like I'm coming across as the victim, um, but I do think that here, for a university that - liberal arts college, humanities, blah, blah, blah. There's this new thing about being more human - humanising the institution. What about the bloody staff?' (Participant W, male)

This disinterest and disregard for who the older generation academic was, also caused staff to become more aware that they were not valued in terms of who they were, but rather for the input they put into the university - which goes against the principles of human resources. The Pension Fund of Rhodes University (2015) goes on to state that staff may be hired on contractual basis after retirement; however, this is not a guarantee for academic staff who wish to be reappointed. This stipulation perpetuates the idea that the university only appoints those who are indispensable and who are still needed by the university for the research output they produce and not for the transferability of their skills. This was particularly true with regard to participant $S$ and participant $\mathrm{W}$, who were needed in terms of their skills:

'And they've kept me on, on contract for one very specific reason, that is that I have an extremely scarce skill within the department. Um, I'm the only person in the department who has a PhD in xxx and, um, so there is just no one to replace me.' (Participant W, male)

Participant S further went on to say that she was happy to be employed back into the university and that she dreaded the day that she would have to retire and would no longer be needed. This is a harsh realisation for some, as they have devoted the majority of their careers to helping students and furthering the development of their particular fields of study. Participant W further emphasised the seriousness of this harsh reality:

'So that was why I was open to being asked to go on, and approaching retirement I found myself a little deliberately teaching the old stuff that nobody wanted to teach. I wanted to kind of make myself as indispensable as possible all right.'

This act of making oneself as indispensable as possible further highlights the reason why academics are forced to retire at some stage, as the university no longer deems them useful. This is very critical to consider as, according to Amos et al. (2008), employees are supposed to be incentivised to stay by human resources, not to incentivise human resources to allow them to stay. This incentivised approach also suggests that the university has no mandatory reason for academics to retire and that the age regulation is only purposeful if the university has no need for the retiring academic. This was particularly the case for participant M, who was seen as no longer needed by the university and whose contract was therefore not renewed:

'They in fact, ah, gave me a renewed, uh, contract and annual contract for, for three, three years. So like three year contract for post-retirement, ah, which had to be fought for. The university wasn't too happy, but, um, and then, last year, that was a one course I did and this year they said "absolutely no ways".

They were quite adamant ... That, um, both $\mathrm{xxx}$ and myself had outlived our usefulness.'

This perpetuates Badat's argument that there is a trade-off between quality and accountability in terms of redressing past injustices and adhering to policies (Badat 2010), but it further identifies the fact that this trade-off is only acceptable if the academic retiring is no longer useful and disposable.

These values held by the university human resources department in terms of their policies and procedures can be seen as dehumanising to the academics at the university for the reason that older generation academic staff are only valued for their skills and input if it is desired.

This realisation as to the message that the university stipulates to academics needs to be addressed, as these policies and procedures are directly affecting the transformation of the university. The efforts of older generation academics need to be realised if the university wishes them to transfer their skills to new generation academics. However, the university can require academics to retire, as their contract does have a retirement age statement; according to the Labour Relations Act of 1995, it states that employees and employers can, within their own capacity, negotiate the terms of this age and suggest possible alternatives should either party deem them beneficial (Department of Labour 2017). This realisation is emphasised by the human capital theory, which states that the skills and experiences of academics need to be invested in (McCracken et al. 2017).

This investment in the older generation academics' skills can be in the form of an open communications system from the university and the acknowledgement of the individual rather than just their credentials and input into the university. This incentivised approach to recognition of the person can allow for the academics to feel the university wishes them to share their skills and that, once they retire, they may do so knowing that their skills and experience will still be valued by the new generation of academics.

\section{Transforming an institution}

Vincent (2015) states that the policies and procedures of an institution may change, but the social and cultural practices 
stay the same. In the case of this university, this has been found to be particularly true. This theme highlights these two viewpoints of Vincent (2015) in that the policies of Rhodes University have remained the same, but the culture of the university misrepresents and clashes with these policies.

\section{'The buzzword'}

Transformation within higher education has been seen to be influenced largely by society and has formed a fundamental part of South African society, post-apartheid (Badat 2010). However, there has been a debate around higher education wherein the practices and the procedures of the institution have remained the same despite the fact that many initiatives have been implemented. Throughout the interviews, the participants came to a consensus that there has been change within the demographics of the institution but that the syllabus and procedures have remained the same.

ParticipantW informed us thathe understood 'transformation' to be a buzzword in terms of the fact that its meaning is whatever anyone perceives it to be and that this is problematic as it only allows for particular aspects of transformation to be seen, whereas others are discriminated against:

'Ya, I'm aware. I've been aware of it very largely as a buzzword and it seems to me from the word go, it seems to me to mean almost anything, mean whatever anybody wants it to mean. A bit of like humpty dumpty.

The words can mean whatever I say. Ah ... and I think it's, to me, a problematic concept. Um, part of my early training in English here was under somebody who was very interested in, it was the field of semantics. What was really the study of meanings and that stuff.

The rhetoric has changed and the race of the people propagating the rhetoric has changed but nothing else has changed.'

This statement further leads to the fact that, although South Africa has transformed post-apartheid in terms of creating equality and improving the lives of those who were oppressed during apartheid, the policies and structures that have allowed this are the same in terms of the Westernised perspective. Cloete et al. (2004) further state this, as they suggest policies have changed but that their intention and implementation are not supplementary, which can lead to certain aspects being ignored. This is further stated by another participant in that they acknowledge the fact that the racial demographics have changed, but the syllabus and the structures of the university remain the same:

‘Well, I suppose, first of all, it's ... it's, ah ... although what's pretty well achieved now is that the demographics have changed. Um ... you know it used to be a white-only university but it's not that anymore, of course ... ah, and I think we're ... that they ... as far as I know, the syllabi are pretty what they were.'

'Well, being honest, the upgrades and upgraded, you know, has been research or something like that. But by and large, it's pretty much the same things that are being taught.' (Participant M, male)

The term 'transformation' is widely debated within higher education, with some arguing that the decolonisation of the institution is important when redressing the past. However, this is not what is required, and according to Simon (2000), the concept of hybridity should be used to describe the transformation of an institution. This idea of hybridity integrates both the Westernised and colonial perspective with that of the African perspective so that they form a relationship of exchange between cultures (Simon 2000). The idea of decolonisation was highlighted in an interview with participant $\mathrm{P}$, who stated that the term 'decolonisation' was problematic:

'And then there's the, there's the question of the curriculum, which has obviously been in, um, on the agenda for the last ... for recent years, one of decolonisation of the curriculum. Which is quite a, um, it's a, it's a tricky area. It's not straightforward.

You can't just ... I, I always think to say it's the same way we must decolonise. One had had to ask ... should one of us say: 'what are the possibilities for decolonisation and what are the limits to it?' (Participant P, male)

Although the idea of decolonisation is highly debated, this article aims specifically to look at it in terms of the idea of hybridity and that this idea of an exchange between cultures has already established itself within the social interactions of the university.

'You know, I've seen the initial patterns of white students staying with white students and black with black and very tentative, you know, up to fully integrated multiracial couples. You know, and the whole thing, and every time I see a vigorous multiracial interaction and student interaction, I think, this is what it's all about.' (Participant W, male)

This is important to realise the fact that, within the transformation of the institution, the social interactions also form part of this process. Participant $W$ went on to say that these social interactions were also what allowed him, as a white male, to connect with students intellectually and emotionally:

'And I also feel I've made some real connections with students and so on. They don't just see me as an old white racist to whom they can't relate, I hope. Um, which is what, you know? So, I think the moral of the language project for me and the wonderful thing about that language project is that I was working with trained professionals across all colour divisions at the time and you know, we were in a partnership and we had a common goal, which was the upliftment and breaking down of this ...'

Within the above extract, participant W spoke directly to the fact that the cultures and social constructs of the university have already started to change and that the commonality in breaking down the structures of inequality was what drove their team to participate in the language project, which he mentioned. However, he further went on to say that the discourses that were dominant within Grahamstown had not allowed these small achievements to be recognised:

'Ya, ya. Um, and of course sadly in Grahamstown, geographically the opportunities to meet across those old divisions were so much greater and yet they were so much more - it's like the ditch was kind of like ...' ( Participant $\mathrm{W}$, male)

This is one of the main areas of transformation that must be addressed: the small interactions and exchanges of cultures 
that are seen within the university are significant, but it should be reflected by the policies and procedures that the university has in place. These policies are not only in terms of the relationship between Rhodes University and the students but also the community as well because of the fact that universities are microcosms of society. This is also acknowledged by the general systems approach which forms part of the congruency model as the inputs and the external environment affects outputs of the university. In addition, in order for the processes to be effective, all the operations and inputs of the organisation need to reflect the needs and wants of the community as well as its employees (Nadler \& Tushman 1983).

\section{The alienation of institutional culture}

The institutional culture at this university, particularly looking at the younger academic staff, has been shown to be quite uninviting, and this culture has led to a divide between the viewpoints of older generation academics and new generation academics, as well as students.

Badat (2010) argues that the older generation academics will need to be replaced and that this will affect new generation academic staff. This is particularly true as it is observed that cultural differences affect the way in which skills are perceived by academic staff as well as students and the community. Throughout the interviews, participants did not perceive the quality of knowledge to be less than that of previous years, but it was noted that many considered new generation academics to be far more pressurised in terms of higher education and the expectations of the institution and the members of the community. One particular example must be noted in terms of the expectations of academics:

'She began to realise they were, they were becoming quite sullen and turned off. And so she engaged with them and she said, 'what's the problem? We seemed to start so well' ... 'No, you are a paraffin teacher' - it's a wonderful metaphor. 'You are a paraffin teacher' - she said, 'well, what do you mean, a paraffin teacher?' So they said: 'have you ever seen a paraffin lamp?' ... 'Yes' ... 'well, it gives out a poor light, doesn't it?' ... 'Yes' ... 'So, you must be like the neon light, you must give out a strong bright light. The fact that you put us in groups means that you don't know the answers' - this is a totally unanticipated construction of ... if you are asking us questions, you don't know the answers. That means you're a paraffin teacher - you don't have enough light in you. A teacher must be like that and give out a strong, constant light.

Now that's - that, I mean, we can sit back and say, well, that's culturally constructed and you can change it but, can you? After 12 years.' ( Participant $W$, male)

The notion of the 'paraffin teacher', according to $\mathrm{W}$, creates the perception that academics are supposedly 'all-knowing' and that their opinion and answers are correct, as they are in a position of superiority. However, this expectation does not allow academics to engage critically with students or other academics, as the cultural expectation of the community and members of the institution is that they must teach students what they know and that what they know must be correct.

In most viewpoints, it is considered that the new generation of academics, who are mostly black scholars, do not believe the culture of the institution to reflect their values and beliefs through the way they are welcomed into the department as well as within lectures (Dash 2015; Hlengwa 2015). This can further decrease the importance of skills transferability; the new generation of academics may feel disinterested in the ideas and knowledge of the older generation academics because they too make new academics feel alienated. This was noted by the participants in the study, with the majority expressing concern over this alienating culture and that this culture is further emphasised by the students and community, as well.

‘But there has been a number of black academics who have been appointed here and have left for one reason or the other - it's quite a debate as to why they have left. Um, and I suppose that in turn relates to another aspect of transformation, and that is, what they call the institutional culture and that is deemed to be quite alienating to a lot of people who come from cultures which are not familiar with the aspects of ... anti-European culture or one of bad terms.' (Participant $\mathrm{P}$, male)

$\mathrm{W}$ also mentions this problem of the institutional culture, as he goes on to say the following:

'Mmm. Have you read, there was that critical seminar that was here a few years ago and I know xxx spoke at it. It was a symposium or something about [name of the university] - but he said coming to this department, there was absolutely no attempt was made to kind of make him feel at home. To just assume that he would, you know? And he found that xxx, he found the culture of this department very different and alien.

You see, I think people of colour, well, I think particularly black people in this town, they are very ... ah, they are much more able to be unlabelled in the larger urban cultures. I mean, this town is still so tremendously divided between black, [which] largely equals poor, you know, and white equals prosperous. You know, and the two sides of the valley kind of spill it out.' (Participant W, male)

This racialisation of how 'black' is associated with being poor and unintelligent and 'white' is associated with being rich and intelligent is a problematic factor within the transformation of higher education - specifically within this university, where the Westernised culture is still emphasised through the structure of the university whereas the African culture is emphasised in the social interactions of the university:

It's very difficult to tell, very difficult. I, I get ... I hear different things, actually, from students. That the first year student comes to the university and likes to see a sort of greying-white male professor lecturing. That's the image that they come to university with - that kind of person.' (Participant $\mathrm{P}$, male)

This viewpoint that participant $\mathrm{P}$ emphasises also allows for the narrative of inequality to be expressed by new generation academic staff, as the policies and procedures may support transformation and redressing of past injustices. However, the institutional culture of the university directly affects this, and this institutional culture affects the way they are perceived by students within the classroom, as stated by $\mathrm{P}$ in the following extract:

'Um, and I also hear that, well, darker academics suffer from that expectation particularly in their interaction with students. 
So there are - I've heard black academics, they get asked questions - not because the students want to get answers to the questions but [...] to test the knowledge and the ability of the lecturer. So there's a lot of, a strong sort of racial dimension there.' (Participant P, male)

This further highlights Badat's (2010) view that there seem to be trade-offs between quality and accountability. Boughey (2002) also states that equity was a core focus of higher institutions to redress past imbalances but that there has also been a shift from equity to skills development in order to create a workforce for economic growth. However, this shift towards skills development hasn't been properly addressed within higher education, as the need for racialisation of the workforce has been seen to show precedence. Badat (2010) states that South African universities need to give attention to redressing injustices of the past in terms of social equity - particularly for black South African women - while at the same time producing and retaining a new generation of academics.

A study conducted in 2006 found that only 36\% of the academic staff in all South African universities come from the African, mixed race and Indian populations, with only $24 \%$ being Africans (Badat 2010). Although these figures show improvement from 1994, they still do not warrant the notion of an equal and diverse enough workforce. Factors that affect these new academic staff, however, are not just the ability to conduct research and publish knowledge but also the fact that retiring staff need to be replaced (Badat 2010). This realisation calls to the fact that older generation academics and their cultures are leaving the institutional environment. Although some of the advantages may be that a new adaptable culture can be implemented into the institution, it is important to consider the skills and knowledge these academics can relay to new generation academics to help them better their understanding in their respective fields.

The human capital theory states that the skills and knowledge of staff need to be invested for growth of the workforce to be achieved (Nufakho et al. 2004). However, the policies around redressing past transgressions and the institutional culture surrounding these policies seem to be creating a barrier, which results in skills being lost as well as the increased sense of an alienating culture for both older generation academics as well as new generation academics. This is as older generation academics feel they are excluded through polices and new generation academics feel they are excluded through the culture of the university. This therefore does not allow for academics to communicate with one another and also creates a divide in their perceptions of their teaching styles and how students respond to them:

'Okay, so for me, transformation must be meaningful, okay. Um, and the thing that has worried me about it as a political hooray word means, white must go, black must arrive and ...' (Participant W, male)

This alienating culture is directly affected by cultural diversity amongst staff as well as within the community; as we can see from the above extract, it is not only higher education institutions that are being affected by the trade-off of equity and accountability but the community as well.

The divide between the policies and the narratives of individuals informed by their cultures is an issue that needs to be addressed at this university. One way in which this article aims to address this, is by looking at the policies of mentorship programmes and suggesting ways in which the policies of the university reflect the institutional culture and the diversity of the social interactions and values of the individuals within Rhodes.

\section{A collaborative approach to mentoring}

Because South African universities have a diverse workforce as well as student population, the policies and programmes that allow for mentorship and training of academic staff must reflect the needs of this diverse workforce. Akojee and Nkomo (2007) and the human capital theory (McCracken et al. 2017) both state that higher quality results will be yielded through a more diversified combination of people as well as resources. Therefore, the programmes implemented within the university that aim to yield these results must make use of the diversified workforce and resources at their disposal.

\section{The gap in New Generation of Academics Programme}

An unobserved issue within nGAP is that the mentors these academics are being assigned to, may not be the most experienced and qualified in their field. However, those that meet this criterion are those of the older generation and who are seen to be of no real value in the transformation of higher education because of their race, age and cultural identity. Booi, Vincent and Liccardo (2016) further emphasise this point, as they argue that equity has been predicated on one's race and gender and that these factors form part of the stipulations as to the implementation of programmes. They further argue that the retention of black academics and senior staff members are challenging components for higher education institutions but that the retention of black staff does not automatically enhance the transformation of the institution (Booi et al. 2016). This study aims to emphasise the importance of both the new generation academics and older generation academics in terms of their skills and knowledge, which are vital to continuation and growth of not just research within the field, but also teaching abilities within the structure of the institution itself - particularly pertaining to their role in the promotion of quality information.

The participants of the study were all asked whether or not they had heard of the nGAP programme, as all participants were seen to be experts in their fields and would therefore have skills and experiences that would be beneficial to new generation academics. Only two of the participants were aware of the programme and none of them had ever been involved since its launch at Rhodes University in 2001. However, participant $\mathrm{M}$ was involved in another mentorship programme that was similar and deemed relevant to the nGAP. When asked about the nGap, participant $S$ said:

'I know about it but I haven't been involved. Not at all.' 
Participant $W$ also acknowledged the fact that he was unaware of the programme in the following extract. In fact, the researcher had to explain what the nGAP was to these academics:

Interviewer: 'Um, the nGAP programme is a next generation academic programme.'

Participant W: 'Oh, all right.'

Interviewer: 'Which has been implemented at [this university] from 2001.'

Participant W: 'I retired in '09 so I should've known about that.'

Participant M, who had taken part in a mentoring programme, suggested that their skills and experiences were used when helping mentor other academic staff members but that there was no formal structure to follow in terms of how to measure progress, the expectations that they as the mentor had or the requirements of the mentee:

'I, I think it ought to, and this place has made, uh, weak attempts, ah, to, um, what's the word I'm looking for? ... um, mentoring, mentorships in someone, uh, a couple of students have been assigned to me in the last few years. Uh, one was a coloured girl who had to work sort of through me while she was here, ah.

$\mathrm{Ah}$, and the other was $\mathrm{xxx}$; I was supposed to mentor them. Nobody asked me for reports or what I was doing. I got no encouragement to mentoring, I had no mentoring training, um, I don't think it was - there was certainly not any incentive ... for me. Ah, cos all it was, you know, get out as soon as you can. Ah, years ago I did some work before I came here [name of the university] around the sort of black advancement story in a company in Durban and it was about the apprentices and were the apprentices helping the new black apprentices - the white apprentices - and the guys said, you know, um, 'voting to support your programme is like a turkey voting for Christmas'. (Participant M, male)

This form of mentorship would not yield correct results according to the human capital theory, as there was no investment of resources or expectations of both parties involved (McCracken et al. 2017). This also emphasised the fact that the mentor was not fully aware of their role, as they had no training in mentorship, and this in turn would affect their relationship with their mentee.

Another aspect that the nGAP took into consideration is that the acquisition of knowledge was important within the programme and that mentees were also given some autonomy in their decision-making and new ways of teaching (Dugmore 2016). However, the observed sentiment from the participants was that academics would not be valued in terms of their teaching abilities but rather for their research and publication abilities and that this research ability and the progression of the $\mathrm{CV}$ was the main contributing factor as to how academics were recognised within the university:

'As far as I know, it's more the position than the skills. I don't think the skills are fully appreciated. I know they do have the lecturer awards and the researcher awards, and my personal opinion is that they often go to the wrong people and I'd like to see awards going to young, developing people who've really shown how they have developed and shown promise. There is one in the faculty, but it's ... everything is so predicated on publications and there's so much more to being a good university lecturer.' (Participant S, female)

Another fact observed by participant $\mathrm{M}$ was that, by the university excluding some academics, it emphasised the fact that certain individuals are only considered based on their roles and certain achievements, which further emphasised the point participant $S$ made above:

'But ya, that's the problem with a small university and excluding people who could be able to help and, no, I think they, um, and they certainly don't go out of the way to defend the skills. Um, I think the university as an organisation is never taught. So it focuses on the educational enterprise rather than on the organisational psychology of Rhodes ...' (Participant M, male)

This idea of publications and research seems to be the predicating factor for the success of academics and that these are the most important skills to have. However, this research ability is important, but it does not address the fact that academics must be able to transfer their knowledge to the students and that, to do so, they must be aware of the skills necessary to present to students and what information is needed for them to present. This type of mentorship needs to be considered within the policies and procedures of Rhodes University and the nGAP is not substantial in this regard.

\section{The informal of the formal}

Although the nGAP is seen to have addressed equity within the institution, as stated by Hlengwa (2015), the formalised structures of the programme does not allow for the transfer of informal skills to take place between older generation academics and new generation academics. All of the participants agreed that they would willingly take part in a mentorship programme that has formal policies in term of implementation but that the programme should be voluntary and informal in the nature of relationships between the mentor and mentee. Another argument that was made by several of the participants was that the head of department should be the main enforcer of the programme, but that the mentee should be able to learn from various mentors and not just one in particular. This was argued because of the fact that the participants felt that the formalisation of having one mentor did not allow the mentee to consider various perspectives as well as engage with others with whom they work and that an informal structure would allow academics to create a two-way learning process where both the mentor and the mentee could develop and grow:

'No, and I think one needs to, to pass on some fundamental ideas, but really, you know, also have room for the student to take them and build them and adjust them to a particular way so, in your case, you know, if you wanted to go into HR, what particular kind of organisations that you would like to go into, what would you - how would you aim to get in there, what you need to achieve that. You know, and so on.' ( Participant R, male)

The comment made by participant $\mathrm{R}$ is important to realise, as he reflected the sentiments made by Hlengwa (2015) in the 
sense that the university should allow the new generation academic to grow within their own field and knowledge and that the culture of the institution should be of their choice as well as reflect their own beliefs and values. This can only be done through a programme that allows both the institution as well as the academic to grow; this was further argued by $S$, in that there needs to be a formalised process that allows this:

'I do think so. I think it's absolutely essential that there is a transfer of skills. And you quite rightly said, it's not necessarily just the academic knowledge that the whole skill of - there's institutional knowledge you want to pass on, there's how to deal with students - that's the, sort of, problems that you have in supervision and looking after students. There's a whole lot of things that don't get passed on and the problem is, there's nothing formalised.' (Participant S, female)

In acknowledging participant S's statement of a formalised structure, it is also important to consider the thoughts of participant $\mathrm{W}$, who suggested that the programme should also allow academics to create a mentorship environment within their departments. He also suggested that, even though it is a formalised programme, the reason for mentorship is to help academics progress - not to ensure that the process be done:

'That you should be encouraged. A new member of staff, a young member of staff should be encouraged to identify somebody on the staff that they feel they could take their problem to. And it might be a different person every time for a different problem, you know?

Um, ah ... So, but I do think that - it, it should be a - I don't want to use that word 'culture', I hate that word 'culture' - but an atmosphere, an environment that encourages an open exchange, but I think it should be free and voluntary.' (Participant W, male)

This idea of creating an environment is interesting to note by participant $\mathrm{W}$ as he suggests a mentorship programme that is open, as he further went on to state:

'Ya, ya. That is, that it should be communicated as: mentorship is one of the things we do. You pick what you want and take what you want and take, and feel free to pick and choose as well as often, as well. Because it's, what ultimately matters is you. The person who you are becoming and we're all still in the process of becoming.' (Participant W, male)

This collective approach to teaching would therefore allow all parties within the mentorship programme to collaboratively work with one another and to create a programme that allows the mentee to grow his or her skills through informal relationships, with many academics helping them develop both their informal and formal abilities that are necessary and that will help them grow within the institution. This type of knowledge production is known as 'organisational learning', where knowledge is a combination of experience, values, contextual information and expert insight that provides a framework for incorporating and evaluating new experiences and information (Amos et al. 2008). This is important to consider when looking at skills transferability from older generation academics to new generation academics; Amos et al. (2008) further goes on to state that this knowledge originates from the minds of knowers - for this study, the minds of the older generation academics.

\section{Conclusion}

To the debate of transformation of the academy, this study brought the important question of skills transferability; ideas for including a more voluntary and practical mentorship programme were suggested that can be employed to try mitigating the noticeable missing link of skills transferability in the sector. Considering the current transformation debates and discourses currently moulding themselves in higher education institutions, it is important to remember the aspect of skills in building the human capital of the workforce and that these skills are needed to further the understanding in knowledge, teaching and understanding of the role higher education plays within the greater society.

Thus, this understanding, although limited to the research conducted within this study and only looking at the context of this university, forms the foundations of research and development into this field of research to build on the discourses of transformation - and aid in the successful implementation of policies of redress and development to move South Africa forward; societally, economically and cultural development.

Therefore, the policies of this university and the value that is placed on academics need to be redressed and evaluated if this collaboration amongst staff members is to be realised. This further perpetuates the need for the policies and procedures to be informal in terms of implementation, as this allows open communication as well as an environment in which academics can approach one another freely. This open and voluntary mentorship programme was expressed by the participants to be a core focus for this university, as the exclusion of academics within the participation of the nGAP programme only allows new academics to gain expertise from those they are assigned to, which only allows the perspectives of one academic to be understood. Participant W described this in his interview when he metaphorically emphasised that skills and experience gained were limited because of the notion that the development of knowledge and transfer of skills was a part of the production process meaning that it was characterised as a 'one size fits all' process:

$[H]$ e and some one hundred and forty other schoolmasters had been lately turned at the same time, at the factory, on the same principles, by so many piano-forte legs. He'd been put through an immense variety of paces in order to out some volumes of headbreaking questions - orthography, entomology, syntax in prosody, biography, astronomy, geography and general cosmography the sciences of compound proportion, land surveying and levelling ... As though it was drawing for models for all of the $n$ 's of his 10 chilled fingers.

Overall, an important realisation that was made within this research study, and in looking at the preceding extract, was that the diversity of cultures does not allow for a one-sizefits-all approach to skills transferability and collaboration 
and that the diversification and allowed growth of new generation academics will only be realised by the institution once the institutional culture embedded in the policies and procedures of the university allows for a dynamic response to teaching. This further emphasises the importance that the skills of older generation academics are needed for new generation academics to advance their experiences and teaching; however, it is not only the transfer of knowledge that is needed but the collaborative effort to allow both parties to grow in their own understanding of their 'being' and their need within the transformation of higher education.

\section{Acknowledgements Competing interests}

The authors declare that they have no financial or personal relationships which may have inappropriately influenced them in writing this article.

\section{Authors' contributions}

S.B. conceptualised the whole study and provided the necessary literature. S.B. also did the second round of corrections. L.M. was S.B.'s postgraduate student. L.M. collected the data for this article and wrote most part of the article. T.K. helped with the first round of reviewers' recommendations. T.K. also contributed in the writing of some sections.

\section{References}

Akojee, S. \& Nkomo, M., 2007, 'Access and quality in South African higher education: The twin challenges of transformation', SAJHE 21(3), 385-399.

Amos, T., Ristow, A., Ristow, L. \& Peasrse, J.P., 2008, Human resource management Oxford University Press, South Africa, Cape Town.

Badat, S., 2010, 'The challenges of transformation in higher education and training institutions in South Africa', paper commissioned by the Development Bank of Southern Africa, viewed 13 June 2016, from https://www.ru.ac.za/.../The $\% 20$ Challenges $\% 20$ of $\% 20$ Transformation $\% 20$ in $\% 20$ High

Berndt, A. \& Petzer, D., 2014, Marketing research, Pearson Education South Africa, Cape Town.

Booi, X., Vincent, L. \& Liccardo, S., 2016, 'Counting on demographic equity to transform institutional cultures at historically white South African universities?', Higher Education and Research Development 36(3), 498-510. https://doi.org/10. 1080/07294360.2017.1289155

Boughey, C., 2002, 'From equity to efficiency: Access to higher education in South Africa', Arts and Humanities in Higher Education 2(1), 65-71. https://doi.org/ 10.1177/1474022203002001006

Braun, V. \& Clarke, V., 2006, 'Using thematic analysis in psychology', Qualitative Research in Psychology 3, 77-101. https://doi.org/10.1191/1478088706qp063oa

Bryman, A., Bell, E., Hirschohn, P., Dos Santos, A., Du Toit, J., Masenge, A. et al., 2014 Research methodology: Business management and context, Oxford University Press, Cape Town.
Cloete, N., Maasen, P., Fehnel, R., Moja, T., Perold, H. \& Gibbon, T., 2004, Transformation in higher education: Global pressures and local realities in South Africa, 2 nd edn. Kluwer Academic Publishers, South Africa, Dordrecht.

Dash, M., 2015, in P. Tabensky \& S. Matthews (eds.), Being at home: Race, institutional culture and transformation at South African Higher Education Institutions, pp. 157-178, University of KwaZulu-Natal Press, Pietermaritzburg.

Department of Higher Education and Training (DHET), 2013, White paper for postschool education and training: Building an expanded, effective and integrated post-school system, Department of Higher Education, pp. 1-96.

Department of Labour, 2017, Labour Relations Act 66 of 1995, Republic of South Africa, pp. 100-113.

Dugmore, H., 2016, Rhodes University: Growing the next generation of academics, Communications and Marketing Division, Grahamstown, pp. 1-49.

Gordon, L.R., 2015, 'Race and justice in higher education: Some global challenges, with attention to the South African context', in P. Tabensky \& S. Matthews (eds.), Being at home: Race, institutional culture and transformation at South African Higher Education Institutions, pp. 157-178, University of KwaZulu-Natal Press, Pietermaritzburg.

HESummit, 2015, 'Reflections on higher education transformation', Higher Education Summit 2, 1-24.

Hlengwa, A., 2015, 'Employing safe bets: Reflections on attracting, developing and retaining the next generation of academics', in P. Tabensky \& S. Matthews (eds.), Being at home: Race, institutional culture and transformation at South African Higher Education Institutions, pp. 147-154, University of KwaZulu-Natal Press, Pietermaritzburg.

Human Resource Development Council, 2015, Production of Academics and Strengthening of Higher Education Partnerships with Industry (PASHEPI), vol. 1, Human Resources Development Council, pp. 1-58.

Makgoba, M.W., 2004, Conceptions of a transformed university: 'South African', 'African', 'Engaged ...', CHE Roundtable Discussion, Council on Higher Education, Pretoria.

McCracken, M., Mclvor, R., Treacy, R. \& Wall, T., 2017, Human capital theory: Assessing the evidence for value and importance of people to organisational success, CIPD, pp. 1-96.

Nadler, D.A. \& Tushman, M.L., 1983, 'A general diagnostic model for organisational behaviour: Applying a congruence perspective', in J.R. Hackman, E.E. Lawler \& L.W. Porter (eds.), Perspectives on behaviour in organisations, pp. 112-125, McGraw-Hill Book Company, New York.

National Treasury, 2004, Retirement fund reform: A discussion paper, National Treasury, Pretoria, pp. 4-69.

Neuman, L.W., 2014, Social research methods: Qualitative and quantitative approaches, 7th edn., London, Pearson.

Nufakho, F. M., Hairston, N. \& Brooks, K., 2004, 'Human capital theory: Implications for human resource development', Human Resource Development International 7(4), 545-551. https://doi.org/10.1080/1367886042000299843

Pension Fund of Rhodes University, 2015, A member's guide to the Rhodes University Pension Fund, Rhodes University, Grahamstown.

Rhodes University, 2014, Full report on the Rhodes University Institutional Culture Survey, Office of Equity and Institutional Culture, Grahamstown, pp. 1-181.

Simon, B., 2000, 'Hybrid America?', in A. Singh \& P. Schmidt (eds.), Postcolonial theory and the United States: Race, ethnicity and literature, p. 415, University Press of Mississippi, Jackson, MS.

South African Government Gazette, 1998, Employment Equity Act, Government Gazette, Prtoria, October 19, pp. 1-28.

Van Bruggen, A.C., 2001, Individual production of social well-being: An exploratory study, University Medical Centre, Groningen, pp. 115-142.

Vincent, L., 2015, “'Tell us a new story”: A proposal for the transformatory potential of collective memory projects', in P. Tabensky \& S. Matthews (eds.), Being at home: Race, institutional culture and transformation at South African Higher Education Institutions, pp. 21-42, University of KwaZulu-Natal Press, Pietermaritzburg.

Waghid, Y., 2002, 'Knowledge production and higher education transformation in South Africa: Towards reflexivity in university teaching, research and community service', Higher Education 7, 457-488. https://doi.org/10.1023/A:1015211718131 